\section{Similarity between neonatal profile and socioeconomic index: a spatial approach}

\author{
Similaridade entre perfil de nascimentos \\ e condições sócio-econômicas: \\ uma análise espacial
}

Eleonora d'Orsi 1,2

Marilia Sá Carvalho 1

Oswaldo Gonçalves Cruz ${ }^{3}$

\footnotetext{
1 Escola Nacional de Saúde Pública, Fundação Oswaldo Cruz, Rio de Janeiro, Brasil.

2 Universidade do Sul

de Santa Catarina,

Tubarão, Brasil.

3 Programa de Computação

Científica, Fundação

Oswaldo Cruz,

Rio de Janeiro, Brasil.

Correspondence

E. d'Orsi

Universidade do Sul de Santa Catarina. Rua das Acácias 121, bloco B3, apto. 401,

Florianópolis, $S C$

88040-560, Brasil.

eleonora.dorsi@terra.com.br
}

\begin{abstract}
This study aims to compare neonatal characteristics and socioeconomic conditions in Rio de Janeiro city neighborhoods in order to identify priority areas for intervention. The study design was ecological. Two databases were used: the Brazilian Population Census and the Live Birth Information System, aggregated by neighborhoods. Spatial analysis, multivariate cluster classification, and Moran's I statistics for detection of spatial clustering were used. A similarity index was created to compare socioeconomic clusters with the neonatal profile in each neighborhood. The proportions of Apgar score above 8 and cesarean sections showed positive spatial correlation and high similarity with the socioeconomic index. The proportion of low birth weight infants showed a random spatial distribution, indicating that at this scale of analysis, birth weight is not sufficiently sensitive to discriminate subtler differences among population groups. The observed relationship between the neighborhoods' neonatal profile (particularly Apgar score and mode of delivery) and socioeconomic conditions shows evidence of a change in infant health profile, where the possibility for intervention shifts to medical services and the Apgar score assumes growing significance as a risk indicator.
\end{abstract}

Spatial Analysis; Live Birth; Socioeconomic Factors

\section{Introduction}

The assessment of aggregate risk is a useful tool to define priorities among areas requiring intervention, based on increased probability of undesirable outcomes 1 . Studies in different countries have shown associations between socioeconomic variables and neonatal conditions, relating low birth weight to social class 2,3 , income 4 , maternal age, number of liveborn children, and the mother's marital status 5, type of health insurance, and health care during pregnancy 6 .

The effects of family income on health status have been exhaustively demonstrated 7,8,9,10,11. Concerning educational level, the proportion of literate women is a classic indicator of socioeconomic level, in addition to access to information. Among demographic indicators, the factor "proportion of households headed by women" has been associated with poverty and economic instability 12 .

Previous studies have shown the importance of socioeconomic indicators related to sewage disposal, income, schooling, and demographic aspects for distinguishing between areas, depending on the geographic scale adopted in the analysis $11,12,13$.

Indices that combine several indicators have been created to jointly describe complex problems such as an area's socioeconomic profile. Two major problems with such indices are the 
selection of valid, feasible indicators 14 and the methodology used to create the indices 15 . The analysis becomes more complex as the number of variables increases, due to the growing frequency of intervening factors, interaction, and colinearity among the observed phenomena. The use of complex indices in conjunction with maximum possible homogeneity in the analysis should minimize this problem 16 . The use of a compound index is necessary to obtain a more accurate estimate of deprivation based on census data. Validation is an important step in establishing the accuracy of any census-based deprivation index 3 .

This study aims to compare neonatal characteristics and socioeconomic factors in specific geographic areas. A socioeconomic classification of Rio de Janeiro neighborhoods was created, based on the described census variables. The population profile was compared to birth indicators in order to discuss the relationship between living and health conditions.

The indicators selected in this study measure different aspects of quality of life. Access to essential services was evaluated through the proportion of households in each neighborhood supplied by the public water and sewerage systems. Urbanization characteristics were measured by: (a) the percentage of census tracts in each area classified as slums ("favelas"); (b) the type of construction (houses or apartments), which results from the process of land occupation; and (c) ownership of the housing (owned versus rented). Rented housing is rare among both the wealthiest families, who live in their own homes, and the poorest, who can neither afford to purchase their own housing or to rent, and thus live in slums. On the other hand, the presence of single-family buildings is more frequent in both the slums and poor outlying neighborhoods. Where land is more expensive, apartment buildings are more common.

\section{Methodology}

This was an ecological study using the neighborhood as the geographic unit. In this collective risk analysis, socioeconomic indicators are the exposure variables and birth conditions are the measured effect or resulting health event.

Data from the 1991 Population Census and the 1994 Live Birth Registry (SINASC) were used to construct the neighborhood indicators for the 153 Rio de Janeiro city neighborhoods.
There were 97,519 live births in Rio de Janeiro in 1994. Using only the records with complete data, the following proportions were calculated: live births with a high Apgar score (above 8); low birth weight (below 2,500g); cesarean sections; adolescent mothers ( $<18$ years); and mothers with high schooling.

Exploratory analyses where performed using S-Plus, and maps were constructed with Mapinfo. Choice of socioeconomic indicators was based on previous studies with the same census database 11,13 and on a correlation matrix of variables in order to avoid colinearity. The selected indicators, all of which were proportions of occurrence, were: single-family buildings (defined as opposed to apartments); households connected to the city sewerage system; rented residences; heads of families with monthly income greater than US\$1,280 (10 times the minimum wage); and census tracts in neighborhoods classified as "favelas". A multivariate classification of the five selected indicators was obtained using the non-hierarchical clustering K-means algorithm, available in SAS. The number of clusters was set at 5 and the number of interactions at 10 . The weight of the variables in the composition of the cluster was measured through the indicator $\mathrm{R}^{2} /\left(1-\mathrm{R}^{2}\right)$, where $\mathrm{R}^{2}$ is the variance within groups and $\left(1-\mathrm{R}^{2}\right)$ the variance between groups. The classes obtained were labeled with letters from "A" through "E".

The spatial pattern of the variables was tested using Moran "I" statistics, available in Stat! software, which measures the spatial auto-correlation (r), 0 denoting complete random spatial distribution and 1 an even spatial pattern. This value is tested, assuming normal distribution, and the probability of random occurrence calculated (p). Neighborhoods in which the number of newborn infants was too small ( $<72$ births) were excluded from the spatial tests.

In order to compare the socioeconomic classification with neonatal conditions, a similarity index (SI) was created. Neonatal indicators were classified into five equal range groups, from 1 to 5 , ordered from the worst to the best prognosis for neonatal survival. The proportion of cesareans was numbered in reverse order, the lower numbers standing for the higher values, because despite implying greater risk to the offspring, cesarean rate in Rio de Janeiro is associated with higher-income mothers 17 . The socioeconomic classes were also numbered, from 1 (group “A”) to 5 (group “E”). The module of the difference between classes of each neona- 
tal indicator and socioeconomic profile varied from 0 (absolutely similar) to 4 (completely opposite).

\section{Results}

\section{Socioeconomic conditions:} census indicators

The proportion of single-family buildings and the proportion of homes connected to the city sewerage system in the 153 neighborhoods varied from zero to $100.0 \%$, with high inter-neighborhood means $(61.2 \%$ and $73.7 \%$, respectively). The median of the proportion of dwellings connected to the sewerage system was also very high, around $90.0 \%$, but with a high standard deviation and some outliers at the low end of the distribution, identifying neighborhoods with no access to the city sewerage system. The median of rented houses was low (approximately $25.0 \%$ ), with a narrow inter-quartile range and few outliers. The proportion of women heads-of-households presented a relatively high median, more than $20.0 \%$, with a narrow range. The proportion of heads-of-households with annual income above US $\$ 1,280$ showed a very low median, narrow range, and numerous outliers at the upper end of the distribution. The median proportion of "favela" census tracts was low, approximately $10.0 \%$, but the range was wide and the outliers indicate that some neighborhoods are composed only of "favelas". The statistical distribution pattern for this variable varied inversely with the proportion of households connected to the city sewerage system.

The results of the cluster analysis, mean values for variables, and total number of neighborhoods are shown for each group created (Table 1). The value for $\mathrm{R}^{2} /\left(1-\mathrm{R}^{2}\right)$, listed on the last line, shows the variables that most contributed to discriminate the clusters: access to the sewerage system and proportion of singlefamily buildings. Neighborhoods were mapped according to the results of the multivariate cluster analysis (Figure 1).

Group A presented the highest proportion of apartment houses (only $18.1 \%$ of the residences are single-family buildings), best sewerage system access, and wealthiest families. The proportion of "favela" census tracts was the lowest (Table 1). The wealthiest areas of the city that historically have received greater investment in urban infrastructure 18 were classified in this group. The 28 neighborhoods, occupied by families with the highest purchasing power, represent the most expensive real estate in the city.

The main differences in group $B$ as compared to A are much smaller proportions of heads-of-households with income greater than 10 times the minimum wage (slightly less than

\begin{tabular}{|c|c|c|c|c|c|c|}
\hline & A & B & $\begin{array}{c}\text { Cluster } \\
\text { C }\end{array}$ & $\mathrm{D}$ & $E$ & $\frac{R^{2}}{\left(1-R^{2}\right)}$ \\
\hline \multicolumn{7}{|l|}{ Socioeconomic indicators } \\
\hline Number of neighborhoods & 28 & 58 & 36 & 7 & 24 & \\
\hline Mean percentage of single-family buildings by neighborhood & 18.1 & 56.6 & 80.5 & 76.9 & 89.2 & 3.5 \\
\hline Mean percentage of sewerage access by neighborhood & 96.3 & 92.0 & 83.2 & 15.8 & 6.5 & 13.1 \\
\hline Mean percentage of rented domiciles by neighborhood & 27.7 & 31.8 & 22.5 & 18.5 & 14.8 & 0.5 \\
\hline Mean percentage of income $>10 \times$ min. wage by neighborhood & 39.2 & 10.4 & 5.4 & 14.8 & 6.6 & 1.6 \\
\hline Mean percentage of slum or "favela" census tracts by neighborhood & 6.2 & 10.6 & 39.0 & 63.2 & 13.0 & 1.5 \\
\hline \multicolumn{7}{|l|}{ Neonatal indicators } \\
\hline Mean percentage of cesareans by neighborhood & 56.8 & 46.6 & 39.5 & 43.1 & 40.2 & \\
\hline Mean percentage of low birth weight by neighborhood & 8.9 & 10.1 & 9.8 & 10.4 & 9.0 & \\
\hline Mean percentage of preterm birth by neighborhood & 6.9 & 7.1 & 6.5 & 7.2 & 5.0 & \\
\hline Mean percentage of Apgar score above 8 by neighborhood & 77.8 & 69.5 & 71.7 & 73.2 & 58.8 & \\
\hline Mean percentage of adolescent mothers by neighborhood & 9.9 & 16.2 & 19.3 & 17.5 & 19.7 & \\
\hline Mean percentage of mothers with high-school education by neighborhood & 59.6 & 37.1 & 22.2 & 29.5 & 23.0 & \\
\hline
\end{tabular}




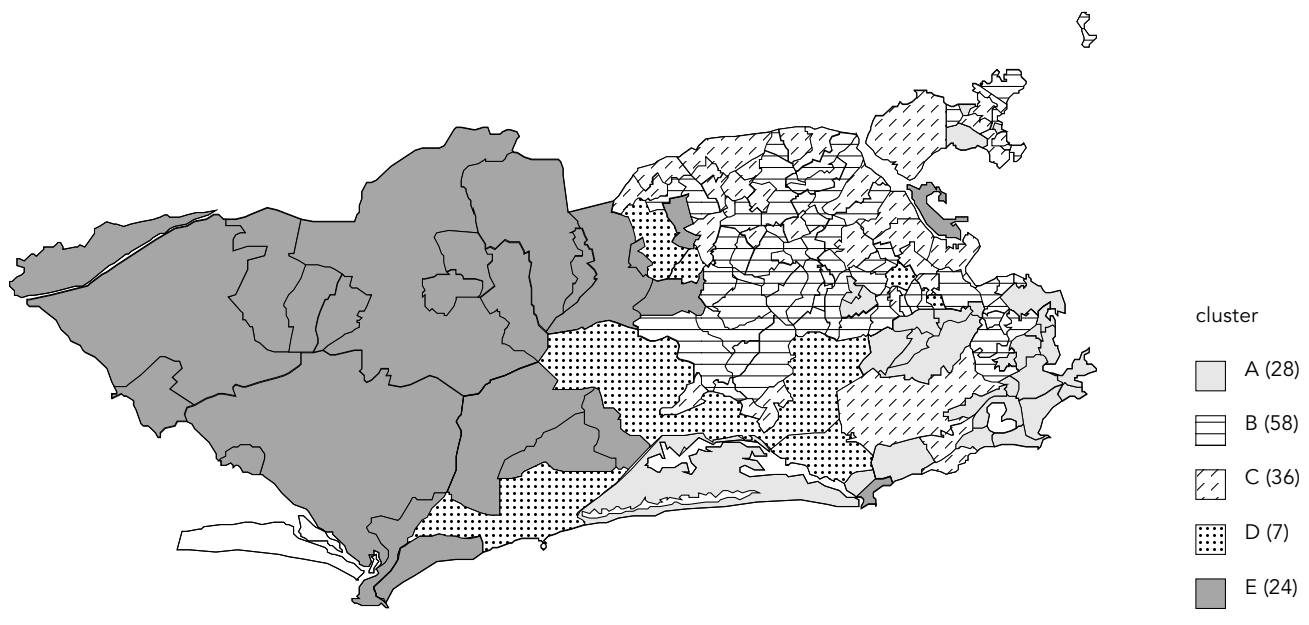

one-fourth) and single-family buildings (56.6\%). "Favelas" were more prevalent in group B neighborhoods. B was the largest group, with 58 areas, and corresponds broadly to the workingclass neighborhoods that accompanied the expansion of the railroad system to the Western Zone of Rio 18.

The predominant characteristic of clusters $\mathrm{C}$ and D was the high proportion of "favela" census tracts $(39.0 \%$ and $63.2 \%$, respectively). Both groups showed a higher proportion of single-family buildings and a smaller proportion of rented houses than A and B. Group C showed a higher proportion of households linked to the city sewerage system and a lower proportion of heads-of-households with incomes above the cutoff (US $\$ 1,280$ ) than group D. The proportion of individuals in cluster D with higher incomes (14.8\%) is curiously high, even higher than in group B. Cluster D is composed of only seven neighborhoods, scattered all over the city, which are rather heterogeneous in social composition, a mix of "favelas" and upper-class areas.

Finally, 24 neighborhoods were classified in group E, comprising nearly the entire Western Zone of the city. Access to the city sewerage system in this group was more precarious, with only $6.5 \%$ of the households connected to the system. "Favela" census tracts were uncommon in group $\mathrm{E}$, because most of the low-cost housing construction programs are conducted in these neighborhoods and the distance from employment areas (more than $50 \mathrm{~km}$, with precarious public transportation) makes them unsuitable for "favelas". Income is similar to that of group C. These are the most recently occupied neighborhoods, and until the 1950s were mostly rural.

\section{Neonatal and socioeconomic conditions: similarity}

According to an analysis of the neonatal health risk indicators for each socioeconomic group (Table 1), the proportion of mothers with a high school education showed the greatest differences between groups $A$ and $E$, with the other three groups in intermediate positions. Another indicator directly linked to social conditions, the proportion of adolescent mothers, presented a reverse profile: the lower the incidence of early pregnancy, the wealthier the group. For Apgar score and proportion of cesarean sections, the profile was less steep, only maintaining the gap between classes A and E. In short, these neonatal indicators showed better health conditions for group A than for group $\mathrm{E}$, with intermediate values for neighborhoods classified in groups B, C, and D. As for low birth weight, the distribution was peculiar: classes $\mathrm{A}$ and E presented the lowest values. The proportions of preterm births oscillated among the groups, without a clear trend.

The Apgar index showed a well-defined spatial pattern (Figure 2), with increasing val- 


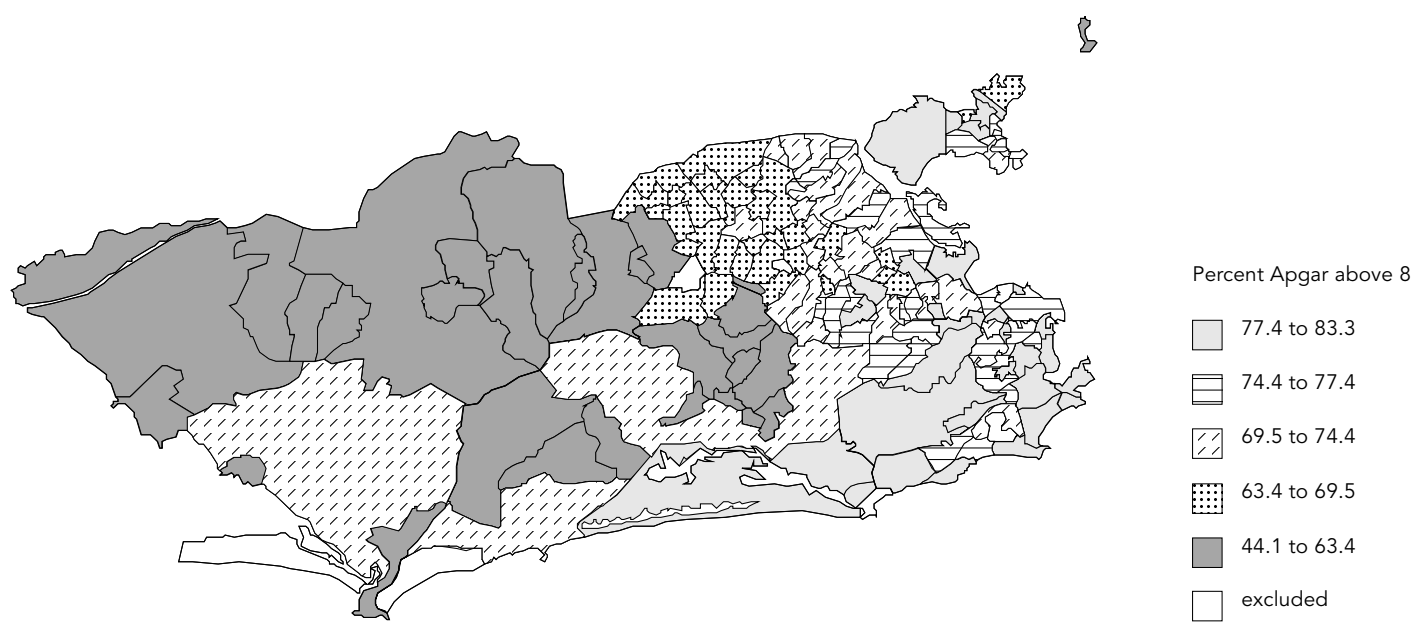

ues from West to East in the city and significant spatial correlation $(r=0.55, \mathrm{p}=0.0000)$. Figure 3a shows the similarity index (SI) for socioeconomic classification and proportion of newborns with a high Apgar score. For neighborhoods classified in groups A and B, the SI indicated high adherence $(\mathrm{SI}=0)$ to this pattern. For most of the areas belonging to groups $\mathrm{C}$ and $\mathrm{E}$, the relationship was nearly as strong $(\mathrm{SI}=1)$. Therefore, for the neighborhoods in Rio de Janeiro, high Apgar score is positively correlated with socioeconomic conditions.

Low birth weight showed a completely different behavior. Spatial distribution of the indicator followed no apparent pattern, and the auto-correlation test was not significant ( $\mathrm{r}=$ $0.07, \mathrm{p}=0.1161$ ). The SI map did not display any spatial pattern either (Figure 3b). Neighborhoods with SI between 0 and 1 were less common and were randomly dispersed among all socioeconomic groups, without any noticeable order. At this level of aggregation - Rio de Janeiro neighborhoods - there was no relationship between socioeconomic classification and low birth weight.

The cesarean rate was also strongly associated with neighborhood socioeconomic conditions (Figure 3c): the wealthier areas presented higher cesarean rates than the poorer ones, with positive auto-correlation test $(r=0.20, p<0.001)$.

\section{Discussion}

The five socioeconomic categories were ranked from A to $\mathrm{E}$, although $\mathrm{E}$ is not necessarily worse than $\mathrm{D}$ in all aspects, or A better than B with respect to all variables. Moreover, there is no $a$ priori certainty about the impact of socioeconomic conditions on population health, despite the known relationship between health and social environment. The impact on neonatal health of being born in a "favela" located in the midst of a wealthy neighborhood or on a small outlying property holding which still maintains rural characteristics is difficult to access.

One limitation of this analysis is that the socioeconomic index and similarity index are not ordinal variables from "better" to "worse" conditions. However, the socioeconomic indicators alone were not capable of characterizing city neighborhoods as adequately as the compound index created through multivariate cluster analysis. We chose this methodology because the similarity index, combining health and socioeconomic status, allowed the comparison of variables in the presence of spatial auto-correlation, where the usual multivariate regression models are not appropriate. We find this methodology useful for distinguishing spatial patterns that could help define priority areas for intervention.

How does one explain the disparity between Apgar and birth weight indicators, both 
Similarity between neonatal characteristics and socioeconomic index. Rio de Janeiro, Brazil, 1994

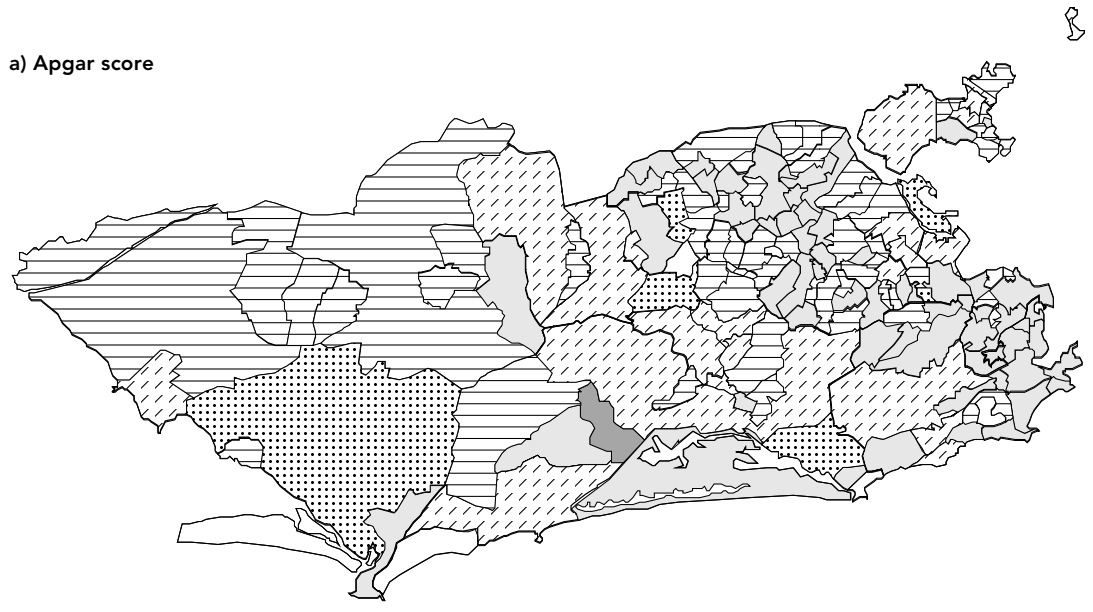

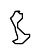
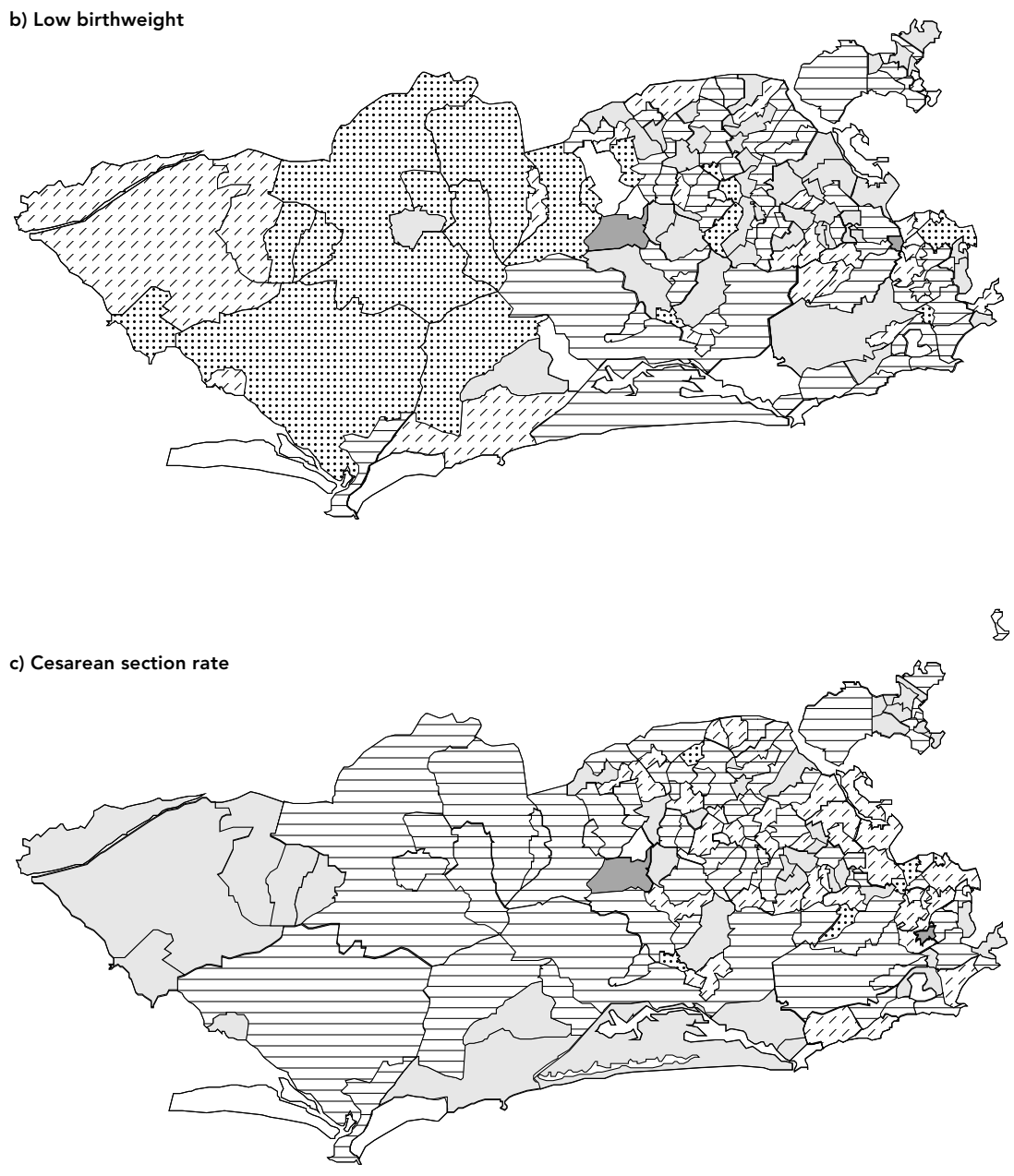
Similarity Index
$\square 0$
$\boxminus 1$
Es 2
3
$\square 4$
$\square$ excluded 
historically related to socioeconomic rank? Low birth weight originates from biological problems, such as diseases during pregnancy, serious maternal malnutrition, and most importantly, preterm birth. At the individual level, there is an unquestionable relationship between poverty and risk of preterm delivery, low birth weight, and various neonatal illnesses. Nevertheless, the analysis of regions with a noticeable socioeconomic gradient suggested that the prevalence of low birth weight and preterm birth determinants leads to no significant difference among neighborhoods. To detect any difference in the behavior of these groups, either the frequency of diseases during pregnancy or inadequate prenatal care should also present a significant disparity among neighborhoods. In Rio de Janeiro, for all purposes, there is no detectable inequality capable of engendering these conditions. For instance, malnutrition as a consequence of socioeconomic deprivation, which in some places can be a serious maternal health problem, is an uncommon condition (no longer endemic) and is thus unable to discriminate among population groups. Other event determinants of low birth weight, such as maternal toxemia and congenital anomalies, are rare and not particularly associated with socioeconomic status (except for access to health care).

The Apgar score, on the other hand, is directly related to quality of childbirth care. Despite the influence of previous intrauterine conditions on fetal vitality, even inadequate care during birth can result in normal birth weight and an Apgar score greater than 8. The research by Campos focusing on neonatal mortality 19,20 corroborate this hypothesis, showing that the spatial pattern of mortality rate by neighborhoods is random. Besides, the flow between the mother's neighborhood of residence and the infant's place of death showed a clear association with socioeconomic profile, whereby the poorest neighborhoods "export" newborns to die in the wealthier ones. Based on its epidemiological characteristics, low birth weight becomes less of a population risk indicator and more of a "sentinel" event for a potentially avoidable outcome, namely infant death.

The cesarean rate in Rio de Janeiro is extremely high. Even in the group with the lowest rate $(39.5 \%)$, the proportion is more than double the $15.0 \%$ recommended by WHO based on clinical guidelines 21 , despite the inherent risk associated with surgical intervention. Several studies have shown the positive association between cesarean rate and socioeconomic level
$19,22,23$. Precisely in social classes with better health and probably less frequent gestational complications, abusive recourse to cesareans suggests that they have become a commodity, dependent on the population's income.

\section{Conclusions}

With regard to neonatal profile, for Rio de Janeiro neighborhoods the proposed socioeconomic classification is predictive of Apgar score, whereby neighborhoods with better living conditions present the highest proportion of children with high Apgar scores. The lack of relationship between low birth weight and socioeconomic index deserves careful interpretation. Traditionally used as the best predictor of neonatal survival, birth weight is heavily conditioned by the mother's socioeconomic status. Nevertheless, the absence of spatial auto-correlation between neighborhoods vis-à-vis the birth weight variable is no longer adequate to grasp differences among liveborn populations. Neighborhoods in Rio de Janeiro encompass wealthy and poor areas, "favelas" and middle-class gated communities, side-by-side, and birth weight is not sensitive enough to discriminate subtler differences among them. The results would probably be different on a finer scale, such as in smaller areas separating "favela" enclaves from wealthier streets, and the role of this indicator would be retrieved.

As for the excessively high cesarean rates, indicating a serious distortion in obstetric practice, the SI pinpoints the wealthier areas, suggesting the central responsibility of private health care in this abuse. Obstetric practice in this wealthier group, where the prenatal physician is supposed to also attend the childbirth, induces a choice of the moment of birth based on the obstetrician's convenience (and possibly also that of the mother), despite the wellknown ill effects of this surgery on both the mother's and infant's health.

The observed relationship between neonatal and socioeconomic conditions by neighborhood, particularly Apgar score and mode of delivery, shows evidence of a change in infant health profile, whereby the possibility for intervention shifts to medical services and the Apgar score assumes growing significance as a risk indicator. 


\section{Resumo}

Este estudo foi realizado com o objetivo de comparar o perfil de nascimentos e as condições sócio-econômicas nos bairros do Município do Rio de Janeiro, Brasil, identificando áreas de risco prioritárias para atuação. Utilizou-se desenho de estudo ecológico. As fontes de dados foram o Censo Demográfico do Instituto Brasileiro de Geografia e Estatística e o Sistema de Informações sobre Nascidos Vivos, agregados por bairros. Foi realizada análise espacial, classificação multivariada pela técnica de "cluster" e estatística "I" de Morin para detecção de autocorrelação espacial. Foi criado indice de similaridade para comparar a classificação sócio-econômica com o perfil de nascimentos. As proporções de nascidos vivos com Apgar acima de $8 e$ cesáreas por bairros apresentaram autocorrelação espacial positiva e alta similaridade com a classificação sócio-econômica. A proporção de nascidos vivos com baixo peso apresentou distribuição espacial aleatória indicando que, nesta escala de análise, o peso ao nascer não é suficientemente sensível para discriminar diferenças entre subgrupos populacionais. As relações observadas sugerem mudanças no perfil de saúde materno-infantil, com necessidade de intervenções voltadas para uso de serviços e crescente importância do escore de Apgar como indicador de risco

Análise Espacial; Nascidos Vivos; Fatores Sócio-econômicos

\section{Contributors}

E. d'Orsi participated in the design, analysis, data interpretation, and drafting of the article. M. S. Carvalho contributed to the design, analysis, data interpretation, and approval of the final version of the article. O. G. Cruz collaborated in the design, analysis, and data interpretation.

\section{References}

1. Hayes MV. On the epistemology of risk: language, logic and social science. Soc Sci Med 1992; 35: 401-7.

2. Almeida LEA, Barbieri MA, Gomes UA, Reis PM, Chiaratti TM, Vasconcelos V. Peso ao nascer, classe social e mortalidade infantil em Ribeirão Preto, São Paulo. Cad Saúde Pública 1992; 8:190-8.

3. Gordon D. Census-based deprivation indices: their weighting and validation. J Epidemiol Community Health 1995; 49 Suppl 2:S39-S44.

4. Victora CG, Barros FC, Huttly SRA, Teixeira AMB, Vaughan JP. Early childhood mortality in a Brazilian cohort: the roles of birthweight and socioeconomic status. Int J Epidemiol 1992; 21:911-5.

5. Rodriguez C, Regidor E, Gutierrez-Fisac JL. Low birth weight in Spain associated with sociodemographic factors. J Epidemiol Community Health 1995; 49:38-42.

6. Katz SJ, Armstrong RW, Lo Gerfo JP. The adequacy of prenatal care and incidence of low birthweight among the poor in Washington State and British Columbia. Am J Public Health 1994; 84:986-91.

7. Costa RA. Bem-estar e indicadores de desigualdade. Revista Brasileira de Estatística 1975; 36:743-52.

8. Arguelo O. Pobreza, población y desarrollo: notas de población. CELADE 1979; (20):73-112.

9. Singer P. Dominação e desigualdade: estrutura de classes e repartição de renda no Brasil. Rio de Janeiro: Paz \& Terra; 1981.

10. Lombardi C, Bronfman M, Facchini LA, Victora CG, Barros FC, Beria JV, et al. Operacionalização do conceito de classe social em estudos epidemiológicos. Rev Saúde Pública 1988; 22:255-65.

11. Cruz OG. Análise da distribuição espacial da mortalidade por homicídios no Estado do Rio de Janeiro em dois períodos: 1980 e 1991 [Tese de Doutorado]. São Paulo: Faculdade de Saúde Pública, Universidade de São Paulo; 1997.

12. Duchiade MP. Mortalidade infantil por pneumonias na região metropolitana do Rio de Janeiro 1976-1980 [Dissertação de Mestrado]. Rio de Janeiro: Escola Nacional de Saúde Pública, Fundação Oswaldo Cruz; 1991

13. Carvalho MS, Cruz OG, Nobre FF. Perfil de risco: método multivariado de classificação sócio-econômica de microáreas urbanas - os setores censitários da Região Metropolitana do Rio de Janeiro. Cad Saúde Pública 1997; 13:635-45.

14. Goldberg M, Dab W. Complex indexes for measuring a complex phenomenon. In: Abelin TH, Brzezinski ZJ, Carstairs VDL, editors. Measurement in health promotion and protection. Copenhagen: World Health Organization; 1987. p. 175-94.

15. Folwell K. Single measures of deprivation. J Epidemiol Community Health 1995; 49 Suppl 2: S51-6.

16. Susser M. The logic in ecological: I. The logic of analysis. Am J Public Health 1994; 84:825-9.

17. d'Orsi E, Carvalho MS. Perfil de nascimentos no Município do Rio de Janeiro: uma análise espacial. Cad Saúde Pública 1998; 14:367-79.

18. Abreu MA. A evolução urbana do Rio de Janeiro. Rio de Janeiro: Empresa Municipal de Informática/Zahar Editores; 1987. 
19. Campos TP, Carvalho MS. Perfil de nascimentos e óbitos infantis: a busca da assistência no Município do Rio de Janeiro. Cad Saúde Pública 1999; 16: 411-20.

20. Campos TP, Carvalho MS, Barcellos CC. Mortalidade infantil no Rio de Janeiro, Brasil: áreas de risco e trajetória dos pacientes até os serviços de saúde. Rev Panam Salud Publica 2000; 8:164-70.

21. Francome C, Savage W. Cesarean section in Britain and the United States $-12 \%$ or $24 \%$ : is either the right rate? Soc Sci Med 1993; 37:1199-218.
22. Rattner D. Sobre a hipótese de estabilização das taxas de cesárea do Estado de São Paulo. Rev Saúde Pública 1996; 30:19-33.

23. Chacham AS, Perpétuo IHO. Determinantes sócio-econômicos da incidência de partos cirúrgicos em Belo Horizonte. In: Anais do X Encontro Nacional de Estudos Populacionais. Caxambu: Associação Brasileira de Estudos Populacionais; 1996. p. 2587-610.

Submitted on 29/Aug/2003

Final version resubmitted on $02 / J u n / 2004$

Approved on 09/Jul/2004 